\title{
Clinical characteristics of 2019 novel coronavirus pneumonia in Zhejiang province, China
}

\author{
LING CHEN $^{1}$, QIUHONG JIN ${ }^{2}$, YING ZHOU ${ }^{1}$, JIAO YANG ${ }^{1}$, ZHEHUA WANG ${ }^{1}$, \\ $\mathrm{KE} \mathrm{GE}^{1}$, JIANGLE YANG ${ }^{1}$ and HONG WANG ${ }^{1}$ \\ ${ }^{1}$ Department of Infectious Disease, Zhejiang Hospital, Hangzhou, Zhejiang 310012; \\ ${ }^{2}$ Department of Infectious Disease, Shengzhou Branch of First Affiliated Hospital of Zhejiang \\ University School of Medicine, Shengzhou, Zhejiang 312400, P.R. China
}

Received March 6, 2020; Accepted June 5, 2020

DOI: $10.3892 / \mathrm{mmr} .2020 .11329$

\begin{abstract}
Since December 2019, an increasing number of cases associated with the 2019 novel coronavirus (2019-nCoV) have emerged in Wuhan, China, which has resulted in a rapid outbreak in China and worldwide. The present study aimed to describe the clinical, laboratory and radiological characteristics of 2019-nCoV pneumonia (NCP) in Zhejiang province, outside of Wuhan. A total of 74 patients with 2019-nCoV were continuously enrolled between January 22 and March 2, 2020 at Zhejiang Hospital. Diagnosis was confirmed at Zhejiang Hospital by reverse transcription-PCR (RT-PCR), which was approved by the Chinese government. Subsequently, the clinical features between positive- and negative-NCP patients in Zhejiang were compared. Among the 74 hospitalized patients with suspected 2019-NCP, six patients (one male and five female patients) were confirmed to be infected with $2019-n \mathrm{CoV}$ by RT-PCR. The average age of the confirmed patients was $40 \pm 13$ years. There were three family clusters among the confirmed cases, one patient from each of these families had travel history or contact with patients from Wuhan within 2 weeks. Compared with non-NCP patients, the most common symptoms at onset for patients with NCP were fever $(5 / 6 ; 83.3 \%)$ and cough $(5 / 6 ; 83.3 \%)$, followed by dyspnea/pharyngalgia $(2 / 6 ; 33.3 \%)$, whereas myalgia $(1 / 6 ; 16.7 \%)$ and fatigue $(1 / 6 ; 16.7 \%)$ were less common. All 74 patients with suspected NCP exhibited abnormal computerized tomography (CT) images. In total, 2/6 $(33.3 \%)$ patients with confirmed NCP presented with bilateral pneumonia, and 21/68 (30.9\%) non-NCP patients exhibited bilateral pneumonia, with bilateral distribution of patchy shadows or ground glass opacity. The present study revealed that epidemiological history was critical to the diagnosis of
\end{abstract}

Correspondence to: Professor Hong Wang, Department of Infectious Disease, Zhejiang Hospital, 1229 Gudun Road, Xihu, Hangzhou, Zhejiang 310012, P.R. China

E-mail: hongwang71@yahoo.com

Key words: 2019 novel coronavirus pneumonia, epidemiological history, reverse transcription-PCR
2019-nCoV in low epidemic regions outside Hubei province. It was also identified that chest $\mathrm{CT}$ could not replace nucleic acid testing due to similar radiological manifestations.

\section{Introduction}

In December 2019, a number of pneumonia cases of unknown origin emerged in Wuhan, China (1,2). On January 7, 2020, the pathogen of these infections was identified by the Chinese Center for Disease Control and Prevention from a throat swab sample; the pathogen was later termed 2019 novel coronavirus (2019-nCoV) (3,4). By March 2, 2020, there were 80,174 confirmed 2019-nCoV cases in China and 8,837 cases in 61 other countries around the world (5). The World Health Organization (WHO) raised the global risk level for 2019-nCoV pneumonia (NCP) to very high on February 22, 2020 (6).

Patients with NCP have clinical features of fever, cough, myalgia, rhinorrhea, fatigue, headache, diarrhea, nausea and vomiting $(2,7,8)$. Chest computerized tomography (CT) is routinely used for diagnosing community-acquired pneumonia, the causative pathogens of which include viruses, bacteria, fungi and atypical pathogens (9). According to recent studies, the majority of patients with laboratory-confirmed 2019-nCoV present with bilateral distribution of patchy shadows or ground glass opacity; however, not every patient has imaging abnormalities $(2,7,10)$. So far, patients with 2019-nCoV can only be confirmed by a nucleic acid test, such as reverse transcription-PCR (RT-PCR) or sequencing (7).

According to the sixth edition of New Coronavirus Pneumonia Prevention and Control Program guidelines (11), patients with suspected NCP are defined as follows: i) Imaging changes characteristic of NCP; ii) fever or respiratory symptoms; iii) normal or decreased white blood cell counts, and reduced lymphocytes counts; and iv) with or without a history of traveling to a NCP-affected area or exposure to patients with NCP within 2 weeks. In view of the high incidence of community-acquired pneumonia in winter, it is difficult to distinguish NCP from pneumonia caused by different pathogens. The purpose of the present study was to describe the clinical, laboratory and radiological characteristics of patients with confirmed 2019-nCoV, and to compare the clinical features with non-NCP patients in Zhejiang province. 


\section{Patients and methods}

Study population. A total of 74 patients with possible 2019-nCoV at Zhejiang Hospital (HangzhouZhejiang, China) were continuously recruited between January 22 and March 2, 2020. Cases were diagnosed on the basis of WHO interim guidance (12). When the suspected patients were admitted to hospital, all were tested using nasal and throat swabs for a RT-PCR assay at Zhejiang Hospital. The confirmed cases were defined as positive for 2019-nCoV nucleic acid by RT-PCR assay (11). Of the 74 suspected cases, six patients were confirmed to be infected with 2019-nCoV and diagnosed as having NCP by CT imaging. These confirmed patients were sent to a designated hospital in Zhejiang and were further confirmed to be positive for 2019-nCoV. Based on the 2019-nCoV nucleic acid test results by RT-PCR assay, the present study population was divided into the confirmed group (NCP-positive cases) and the control group (NCP-negative cases). The present study was approved by the Ethics Review Committee of Zhejiang Hospital, and written informed consent was obtained from all patients.

Data collection. The epidemiological, clinical, laboratory and CT scan data were obtained from electronic records. Recorded information included demographic data, exposure history, smoking history, any comorbidities, signs, symptoms, laboratory findings and CT scans. Laboratory findings were composed of complete blood count, C-reactive protein and direct antigen influenza $\mathrm{A}+\mathrm{B}$ test.

RT-PCR detection. Total RNA was extracted from $140 \mu 1$ nasal and throat swab epithelial cells from each patient using an RNA Isolation kit (Paramagnetic Beads Column; Shanghai ZJ Bio-tech Co., Ltd.), according to the manufacturer's instructions; a $50 \mu 1$ elution was obtained for each sample. A volume of $10 \mu$ l RNA was subsequently used for the RT-PCR, which was performed using a Novel Coronavirus Nucleic Acid Diagnostic kit (SanSure Biotech Inc.), which targeted the 2019-nCoV open reading frame lab (ORF1ab) and nucleocapsid protein (NP) genes. The reaction mixture contained $26 \mu \mathrm{l}$ PCR reaction solution (4.62\% primer, $1.15 \%$ probe, $3.85 \%$ dNTP and $89.13 \%$ PCR buffer), $4 \mu 1$ PCR enzyme mixture (62.5\% RT enzyme and $37.5 \%$ Taq enzyme) and $10 \mu 1$ RNA template. An ABI7500 real-time fluorescence quantitative PCR instrument (Applied Biosystems; Thermo Fisher Scientific, Inc.) was used for detection. The following thermocycling conditions were used for the RT-PCR: Reverse transcription at $50^{\circ} \mathrm{C}$ for $30 \mathrm{~min}$ and initial denaturation at $95^{\circ} \mathrm{C}$ for $1 \mathrm{~min}$; followed by 45 cycles of denaturation at $95^{\circ} \mathrm{C}$ for $15 \mathrm{sec}$ and annellation and elongation at $60^{\circ} \mathrm{C}$ for $30 \mathrm{sec}$; a final extension step was performed at $25^{\circ} \mathrm{C}$ for $10 \mathrm{sec}$. The presence of the two targets (ORF1ab and NP) was determined as positive by specific RT-PCR and the case was considered to be laboratory-confirmed, as previously described (13). A quantitation cycle $(\mathrm{Cq})$ value of $\leq 40$ was defined as positive, while a $\mathrm{Cq}$ value of $>40$ was defined as negative. Three replicates were performed for each sample.

Statistical analysis. Continuous variables are presented as the mean \pm standard deviation. Categorical variables are presented as frequency and percentage. Continuous variables were compared between groups using an unpaired Student's $t$-test. Categorical variables were compared using $\chi^{2}$ or Fisher's exact test as appropriate. Analyses were performed using SPSS v. 20 (IBM Corp.). $\mathrm{P}<0.05$ was considered to indicate a statistically significant difference.

\section{Results}

Basic characteristics. The recruited 74 hospitalized patients were suspected to have $\mathrm{NCP}$ and all influenza antigen tests were negative. In total, six of the suspected patients were confirmed to have NCP by RT-PCR. The other 68 patients were determined to be negative by two nucleic acid tests $\geq 24 \mathrm{~h}$ apart. At the time of publication, the 68 patients had not been diagnosed with NCP at any other hospital, according to follow-up by telephone.

Epidemiological characteristics. The six confirmed patients were from three family clusters, including a couple, and two mothers and daughters. The husband of the couple had been in close contact with his relatives in Hubei province, who had fever or respiratory symptoms; therefore, it is presumed that he infected his wife. One daughter had close contact with a colleague from Wuhan at the annual meeting of her company and is believed to have transmitted the novel coronavirus to her mother. Finally, the mother in the third family cluster flew back to Hangzhou from Wuhan on January 22, 2020 and is believed to have infected her daughter. Therefore, epidemiological history was a crucial factor in the diagnosis of $\mathrm{NCP}(\mathrm{P}=0.004)$.

Demographic and clinical characteristics. The demographic and clinical characteristics are presented in Table I. In total, $83.3 \%$ of the patients with NCP were female, with a mean age of 40 years. On admission, the most common symptoms at onset of NCP were fever $(5 / 6 ; 83.3 \%)$ and cough $(5 / 6 ; 83.3 \%)$, followed by dyspnea/pharyngalgia $(2 / 6 ; 33.3 \%)$; myalgia $(1 / 6$; $16.7 \%)$ and fatigue $(1 / 6 ; 16.7 \%)$ were less common. Compared with the non-NCP patients in the present study, patients with $\mathrm{NCP}$ were more likely to present with dyspnea $(\mathrm{P}=0.05)$. However, other symptoms and comorbidities were similar in the patients with NCP and non-NCP patients (all P>0.05).

Laboratory findings. Laboratory findings and the radiological manifestations are presented in Table II. Patients with NCP had lower lymphocyte counts compared with non-NCP patients, but this was not statistically significant $(\mathrm{P}=0.778)$. Compared with non-NCP patients, patients with NCP had significantly lower levels of $\mathrm{C}$-reactive protein $(\mathrm{P}<0.001)$.

Radiological findings. All 74 suspected patients with NCP exhibited abnormal CT images on admission. Two patients with NCP displayed bilateral pneumonia, and three other patients with NCP exhibited a unilateral distribution of patchy shadows or ground glass opacity, and the other patient with NCP presented with ground-glass nodules. Among the 68 non-NCP patients, 21 (30.9\%) patients demonstrated bilateral pneumonia, with a bilateral distribution of patchy shadows or ground glass opacity. As a result, chest CT imaging of patients with NCP was similar to that of non-NCP patients with pneumonia caused by unknown pathogens (Fig. 1). 
Table I. Clinical characteristics of 74 patients infected with suspected 2019-NCP.

\begin{tabular}{|c|c|c|c|c|}
\hline Characteristic & All patients $(n=74)$ & NCP-positive $(n=6)$ & NCP-negative $(n=68)$ & P-value \\
\hline Age, years & $40 \pm 13$ & $40 \pm 13$ & $40 \pm 13$ & 0.967 \\
\hline Male $(\%)$ & $31(41.9)$ & $1(16.7)$ & $30(44.1)$ & 0.391 \\
\hline Positive epidemiological history (\%) & $31(41.9)$ & $6(100)$ & $25(36.8)$ & 0.004 \\
\hline Current smoking status $(\%)$ & $13(17.6)$ & $0(0)$ & $13(19.1)$ & 0.300 \\
\hline \multicolumn{5}{|l|}{ Comorbidities $(\%)$} \\
\hline Hypertension & $12(16.2)$ & $0(0)$ & $12(17.6)$ & 0.261 \\
\hline Diabetes & $5(6.8)$ & $1(16.7)$ & $4(5.9)$ & 0.353 \\
\hline Thyroid disease & $2(2.7)$ & $0(0)$ & $2(2.9)$ & 0.843 \\
\hline Chronic kidney disease & $3(4.1)$ & $0(0)$ & $3(4.4)$ & 0.773 \\
\hline Pulmonary tuberculosis & $2(2.7)$ & $1(16.7)$ & $1(1.5)$ & 0.157 \\
\hline Chronic liver disease & $5(6.8)$ & $1(16.7)$ & $4(5.9)$ & 0.353 \\
\hline \multicolumn{5}{|l|}{ Signs and symptoms (\%) } \\
\hline Fever & $51(68.9)$ & $5(83.3)$ & $46(67.6)$ & 0.389 \\
\hline Cough & $63(85.1)$ & $5(83.3)$ & $58(85.3)$ & 0.897 \\
\hline Dyspnea & $5(6.8)$ & $2(33.3)$ & $3(4.4)$ & 0.050 \\
\hline Myalgia & $17(23.0)$ & $1(16.7)$ & $16(23.5)$ & 0.580 \\
\hline Fatigue & $10(13.5)$ & $1(16.7)$ & $9(13.2)$ & 0.814 \\
\hline Pharyngalgia & $23(31.1)$ & $2(33.3)$ & $21(30.9)$ & 0.611 \\
\hline Headache and dizziness & $13(17.6)$ & $1(16.7)$ & $12(17.6)$ & 0.717 \\
\hline Rhinorrhea & $5(6.8)$ & $0(0)$ & $5(7.4)$ & 0.647 \\
\hline
\end{tabular}

$\mathrm{NCP}$, novel coronavirus pneumonia.

Table II. Laboratory findings and radiological manifestations of patients with suspected 2019-NCP.

\begin{tabular}{|c|c|c|c|c|}
\hline Characteristics & All patients $(n=74)$ & NCP-positive $(n=6)$ & NCP-negative $(n=68)$ & P-value \\
\hline White blood cell count, $10^{9} / 1$ & $6.6 \pm 2.4$ & $7.6 \pm 3.8$ & $6.6 \pm 2.3$ & 0.308 \\
\hline Neutrophil count, $10^{9} / 1$ & $4.4 \pm 2.1$ & $5.5 \pm 3.6$ & $4.3 \pm 1.9$ & 0.449 \\
\hline Lymphocyte count, $10^{9} / 1$ & $1.7 \pm 0.7$ & $1.6 \pm 0.6$ & $1.7 \pm 7.3$ & 0.778 \\
\hline Monocyte count, $10^{9} / 1$ & $0.4 \pm 0.2$ & $0.4 \pm 0.2$ & $0.4 \pm 0.2$ & 0.934 \\
\hline Hemoglobin, g/l & $144 \pm 18$ & $133 \pm 18$ & $145 \pm 17$ & 0.116 \\
\hline Platelet count, $10^{9} / 1$ & $217 \pm 58$ & $234 \pm 65$ & $216 \pm 57$ & 0.461 \\
\hline C-reactive protein, mg/l & $13 \pm 19$ & $3 \pm 3$ & $13 \pm 19$ & $<0.001$ \\
\hline Bilateral pneumonia (\%) & $23(31.1)$ & $2(33.3)$ & $21(30.9)$ & 0.611 \\
\hline
\end{tabular}

$\mathrm{NCP}$, novel coronavirus pneumonia.

\section{Discussion}

The present study reported that six patients from a total of 74 patients with suspected 2019-nCoV at Zhejiang Hospital were confirmed as having $2019-\mathrm{nCoV}$ by RT-PCR. In the current study, patients infected with 2019-nCoV presented with fever, cough, dyspnea, pharyngalgia, and patchy shadowing or ground glass opacity on chest CT scans; these symptoms are similar to those associated with severe acute respiratory syndrome-coronavirus and Middle East respiratory syndrome-coronavirus infections $(14,15)$. None of the patients with NCP exhibited rhinorrhea, which indicated that the target cells may be located in the lower airway, accounting for why patients with NCP more frequently experienced dyspnea in the present study.

Until now, numerous studies have reported that a large proportion of patients with $2019-\mathrm{nCoV}$ are male. However, the present study observed more women than men with 2019-nCoV, which is contradictory to other studies $(2,7,16)$. The explanation for this may be that the number of patients diagnosed with NCP in Zhejiang was relatively small, thus it was difficult to evaluate the gender distribution of a highly infected population, such as in Wuhan. Further studies are needed to validate the present findings. When the Wuhan 2019-nCoV outbreak occurred, the 


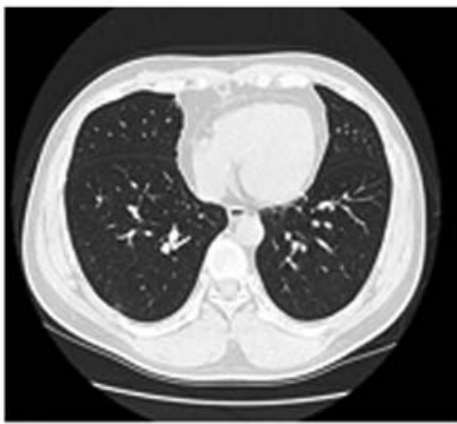

2019-nCoV no. 4

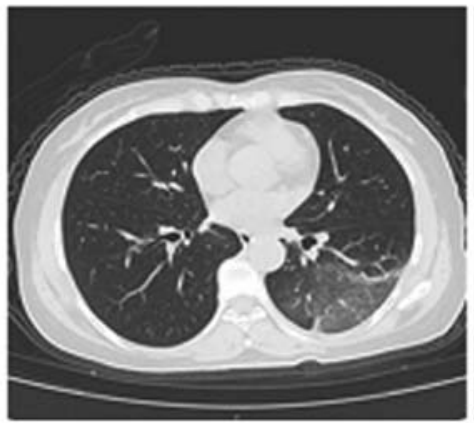

Other pathogen no. 14

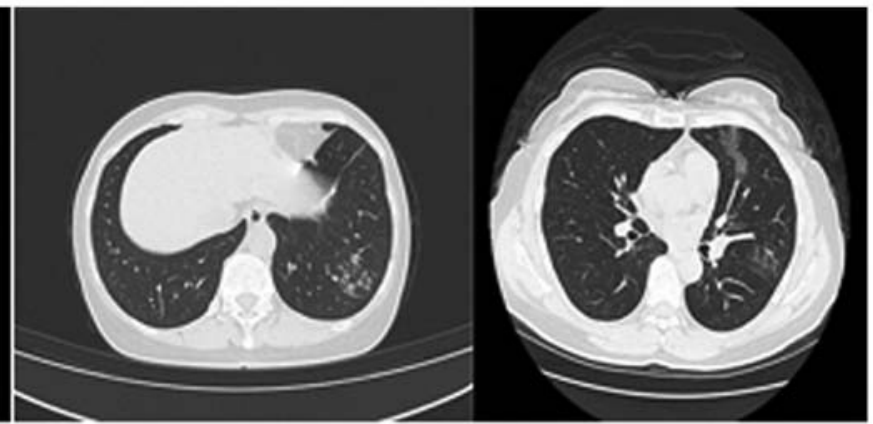

2019-nCoV no. 6

2019-nCoV no. 7

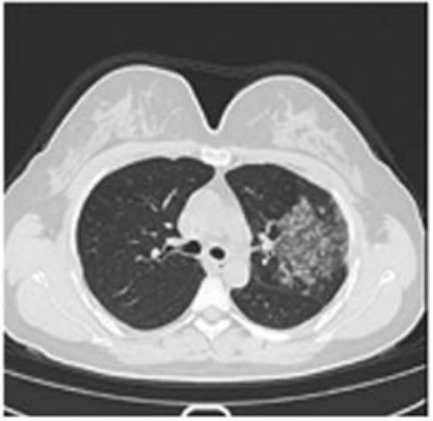

Other pathogen no. 69

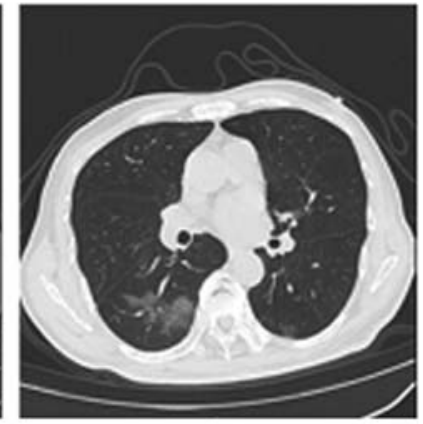

Other pathogen no. 73

Figure 1. Chest computerized tomographic images of patients with 2019-nCoV and pneumonia caused by other pathogens. nCoV, novel coronavirus.

Zhejiang provincial government immediately responded and implemented strict controls, including early identification of patients with NCP and epidemiological investigations of the confirmed patients, thereby cutting off the transmission route to control the spread of NCP in Zhejiang province, which could explain the small number of confirmed patients with NCP in the Zhejiang province. Currently, diagnosis of patients with suspected NCP is based on the following Chinese guidelines: i) A positive epidemiological history, particularly exposure to the Wuhan epidemic area, plus any two clinical manifestations (fever or respiratory symptoms, lower white blood cell and/or lymphocyte count, characteristic imaging of NCP); or ii) if there was no epidemiological history, three clinical manifestations are required (11). The present study demonstrated that for patients with confirmed NCP, epidemiological history was the most important condition for diagnosis. It was revealed that chest CT imaging of patients with NCP was absent of specific manifestations when compared with community-acquired pneumonia; therefore, it was difficult to distinguish NCP from other types of pneumonia using chest CT only $(17,18)$. With the development of the NCP epidemic, an increasing number of patients in Wuhan could not undergo nucleic acid testing in a timely manner, making the diagnosis of suspected patients more difficult. A local clinician in Wuhan had appealed to use chest CTs for diagnosis instead of nucleic acid testing. Clinical CT diagnosis cases were specifically developed for Hubei province based on the fifth edition guidelines. With the greatly enhanced nucleic acid detection capabilities in Hubei province, the sixth edition of the guidelines removed the content of clinical diagnosis $(11,19)$. Therefore, a large number of the diagnosed patients with NCP were not actual NCP cases. The levels of $\mathrm{C}$-reactive protein are usually normal or slightly elevated in patients with viral pneumonia (20), and NCP is also a type of viral pneumonia. In cases of bacterial infections, C-reactive protein levels may increase from a moderate to a high level; for example, C-reactive protein levels exceeded $100 \mathrm{mg} / 1$ in $80 \%$ of patients with sepsis and $>50 \mathrm{mg} / \mathrm{l}$ in $88-94 \%$ of patients with other infections in previous studies $(21,22)$. As is well understood, non-NCP is a type of community-acquired pneumonia caused by other viruses, bacteria and atypical pathogens, but most commonly bacteria (9). Patients with NCP confirmed in the present study were classified as common (no respiratory failure, shock or other organ failure) based on Chinese guidelines. This may explain why C-reactive protein was higher in non-NCP patients compared with patients with NCP.

According to Chinese guidelines, the gold standard for diagnosing 2019-nCoV is a nucleic acid test, such as RT-PCR or metagenomics sequencing (11); however, the latter is expensive and relatively time consuming. Therefore, it is impossible to apply metagenomics sequencing as a preliminary screening method for all suspected patients. By contrast, RT-PCR is relatively cheap and more practical.

In conclusion, given that NCP has been established as a global health threat, how to identify patients with NCP from suspected patients is the first step to control the spread of the NCP epidemic worldwide. For low epidemic regions outside Wuhan, epidemiological history has been critical for the diagnosis of 2019-nCoV. Nucleic acid testing is the gold standard and chest $\mathrm{CT}$ should not replace nucleic acid testing, due to the absence of specific radiological presentations.

\section{Acknowledgements}

Not applicable. 


\section{Funding}

No funding was received.

\section{Availability of data and materials}

All data generated or analyzed during this study are included in this published article.

\section{Authors' contributions}

LC designed the study and wrote the manuscript. HW and QHJ revised the manuscript and interpreted the data. YZ, JY and ZHW performed the experiments. KG and JLY analyzed the data. All authors read and approved the final manuscript.

\section{Ethics approval and consent to participate}

The present study was approved by the Ethics Review Committee of Zhejiang Hospital and written informed consent was obtained from all patients.

\section{Patient consent for publication}

All patients provided consent for publication.

\section{Competing interests}

The authors declare that they have no competing interests.

\section{References}

1. Lu H, Stratton CW and Tang YW: Outbreak of pneumonia of unknown etiology in Wuhan, China: The mystery and the miracle. J Med Virol 92: 401-402, 2020.

2. Huang C, Wang Y, Li X, Ren L, Zhao J, Hu Y, Zhang L, Fan G, $\mathrm{Xu}$ J, Gu X, et al: Clinical features of patients infected with 2019 novel coronavirus in Wuhan, China. Lancet 395: 497-506, 2020.

3. Paules CI, Marston HD and Fauci AS: Coronavirus infections-more than just the common cold. JAMA, 2020 (Ahead of print).

4. World Health Organization: Novel coronavirus (2019-nCoV) situation report-15. Published February 4, 2020. https://www.who.int/docs/default-source/coronaviruse/ situation-reports/20200204-sitrep-15-ncov.pdf?sfvrsn=88fe8ad6_2 http://2019ncov.chinacdc.cn/2019-nCoV/. Accessed February 3, 2020.

5. Centers for Disease Control and Prevention. http://2019nCoV. chinacdc.cn/2019-nCoV. Accessed March 2, 2020.

6. https://www.who.int. Accessed February 28, 2020.

7. Chen N, Zhou M, Dong X, Qu J, Gong F, Han Y, Qiu Y, Wang J, Liu Y, Wei Y, et al: Epidemiological and clinical characteristics of 99 cases of 2019 novel coronavirus pneumonia in Wuhan, China: A descriptive study. Lancet 395: 507-513, 2020.

8. Chang, Lin M, Wei L, Xie L, Zhu G, Dela Cruz CS and Sharma L: Epidemiologic and Clinical Characteristics of Novel Coronavirus Infections Involving 13 Patients Outside Wuhan, China. JAMA 323: 1092-1093, 2020.
9. Metlay JP, Waterer GW, Long AC, Anzueto A, Brozek J, Crothers K, Cooley LA, Dean NC, Fine MJ, Flanders SA, et al: Diagnosis and treatment of adults with community-acquired pneumonia. An official clinical practice guideline of the American thoracic society and infectious diseases society of America. Am J Respir Crit Care Med 200: e45-e67, 2019.

10. Wang D, Hu B, Hu C, Zhu F, Liu X, Zhang J, Wang B, Xiang H, Cheng Z, Xiong Y, et al: Clinical Characteristics of 138 Hospitalized Patients With 2019 Novel Coronavirus-Infected Pneumonia in Wuhan, China. JAMA 323: 1061-1069, 2020.

11. New coronavirus pneumonia prevention and control program (6th edtion) (In Chinese). http://www.nhc.gov.cn/yzygj/s7653p/2020 02/8334a8326dd94d329df351d7da8aefc2 shtml?from=timeline. Accessed February 19, 2020.

12. World Health Organization. Clinical management of severe acute respiratory infection when Novel coronavirus $(\mathrm{nCoV})$ infection is suspected: interim guidance. Published January 28, 2020. https://www.who.int/publications/i/item/ clinical-management-of-severe-acute-respiratory-infectionwhen-novel-coronavirus-(ncov)-infection-is-suspected. Accessed January 31, 2020.

13. Li Q, Guan X, Wu P, Wang X, Zhou L, Tong Y, Ren R, Leung KSM, Lau EHY, Wong JY, et al: Early transmission dynamics in Wuhan, China, of novel coronavirus-infected pneumonia. The New England journal of medicine 382: 1199-1207, 2020.

14. Lee N, Hui D, Wu A, Chan P, Cameron P, Joynt GM, Ahuja A, Yung MY, Leung CB, To KF, et al: A major outbreak of severe acute respiratory syndrome in Hong Kong. N Engl J Med 348: 1986-1994, 2003

15. Assiri A, Al-Tawfiq JA, Al-Rabeeah AA, Al-Rabiah FA, Al-Hajjar S, Al-Barrak A, Flemban H, Al-Nassir WN, Balkhy HH, Al-Hakeem RF, et al: Epidemiological, demographic, and clinical characteristics of 47 cases of Middle East respiratory syndrome coronavirus disease from Saudi Arabia: A descriptive study. Lancet Infect Dis 13: 752-761, 2013.

16. Wu Z and McGoogan JM: Characteristics of and important lessons from the coronavirus disease 2019 (COVID-19) outbreak in China: Summary of a report of 72314 cases from the chinese center for disease control and prevention. JAMA 2020 (Ahead of print).

17. Shiley KT, Van Deerlin VM and Miller WT Jr: Chest CT features of community-acquired respiratory viral infections in adult inpatients with lower respiratory tract infections. J Thorac Imaging 25: 68-75, 2010.

18. Tanaka N, Matsumoto $\mathrm{T}$, Kuramitsu T, Nakaki H, Ito K, Uchisako H, Miura G, Matsunaga N and Yamakawa K: High resolution $\mathrm{CT}$ findings in community-acquired pneumonia. J Comput Assist Tomog 20: 600-608, 1996.

19. 2020 National Health Commision of the People's Republic of China. New coronavirus pneumonia prevention and control program (5th edition). http://www.nhc.gov.cn/yzygj/s7653p/202 002/3b09b894ac9b4204a79db5b8912d4440.shtml.

20. Kruger S, Ewig S, Papassotiriou J, Kunde J, Marre R, von Baum H, Suttor N and Welte T; CAPNETZ Study Group: Inflammatory parameters predict etiologic patterns but do not allow for individual prediction of etiology in patients with CAP: Results from the German competence network CAPNETZ. Respir Res 10: 65, 2009.

21. Le Gall C, Desideri-Vaillant C and Nicolas X: Significations of extremely elevated C-reactive protein: About 91 cases in a French hospital center. Pathol Biol (Paris) 59: 319-320, 2011 (In French).

22. Vanderschueren S, Deeren D, Knockaert DC, Bobbaers H, Bossuyt X and Peetermans W: Extremely elevated C-reactive protein. Eur J Intern Med 17: 430-433, 2006. 